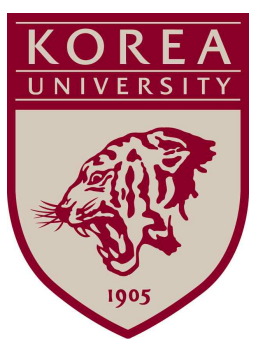

Discussion Paper Series

No. 2001

April 6, 2020

Why has the U.S. economy stagnated since the Great Recession?

Yunjong Eo James Morley

The Institute of Economic Research - Korea University

Anam-dong, Sungbuk-ku, Seoul, 136-701, South Korea, Tel: (82-2) 3290-1632, Fax: (82-2) 928-4948

Copyright (C) 2020 IER. 


\title{
Why has the U.S. economy stagnated since the Great Recession?*
}

\author{
Yunjong $\mathrm{Eo}^{\dagger}$ \\ Korea University
}

\author{
James Morley \\ University of Sydney
}

April 6, 2020

\begin{abstract}
Since the Great Recession in 2007-09, U.S. real GDP has failed to return to its previously projected path, a phenomenon widely associated with secular stagnation. We investigate whether this stagnation was due to hysteresis effects from the Great Recession, a persistent negative output gap following the recession, or slower trend growth for other reasons. To do so, we develop a new Markov-switching time series model of output growth that accommodates two different types of recessions, those which permanently alter the level of real GDP and those with only temporary effects. We also account for structural change in trend growth. Estimates from our model suggest that the Great Recession generated a large persistent negative output gap rather than any substantial hysteresis effects, with the economy eventually recovering to a lower trend path which appears to be due to a reduction in productivity growth that began prior to the onset of the Great Recession.
\end{abstract}

Keywords: Secular stagnation; Great Recession; output gap; trend growth; Markov switching; structural breaks

JEL classification: C22; C51; E32; E37

${ }^{*}$ We thank James Bullard, Ana Galvao, Nicolas Groshenny, Yu-Fan Huang, Susumu Imai, Ryo Jinnai, Chang-Jin Kim, Ian King, Mengheng Li, Charles Nelson, Masao Ogaki, Jeremy Piger, Ben Wang, and conference and seminar participants at the 2018 Norges Bank Workshop on Nonlinear Models in Macroeconomics and Finance, 2018 SNDE meetings in Tokyo, the 2018 International Symposium on Econometric Theory and Applications in Sydney, the 2018 IAAE conference in Montreal, the 2019 Renmin University of China School of Finance Workshop, the Bank of Japan, University of Adelaide, Hitotsubashi University, Hokkaido University, Keio University, Macquarie University, Monash University, Sun-yat Sen University, Universitat Pompeu Fabra, University of Queensland, and University of Technology Sydney for helpful comments and suggestions.

${ }^{\dagger}$ Yunjong Eo: Department of Economics, Korea University, Seoul 02841, South Korea; Tel: +82 23290 2212; Email: yunjongeo@korea.ac.kr

${ }^{\ddagger}$ James Morley: School of Economics, University of Sydney, NSW 2006, Australia; Tel: +61 293513368 ; Email: james.morley@sydney.edu.au 


\section{Introduction}

The slow growth of the U.S. economy in the wake of the Great Recession has led to a revival of earlier notions of secular stagnation (Hansen, 1939) and hysteresis (Blanchard and Summers, 1986). There are different theories of secular stagnation, but Summers (2014, 2015) emphasizes the role of inadequate demand. According to his view, the global financial crisis at the time saw an unwinding of a financial bubble that had propped up the world economy. In its absence and in the face of the zero-lower-bound that prevented a further lowering of interest rates, inadequate demand caused the economy to grow at a slower rate than otherwise. This theory is related to the idea that inadequate demand resulting from the Great Recession may have produced hysteresis or even 'super-hysteresis' effects (Ball, 2014; Guerron-Quintana and Jinnai, 2019) that have permanently lowered both the level and growth path of economic activity. Using data from 23 countries, Blanchard, Cerutti and Summers (2015) document that many recessions have led to such effects, although they acknowledge that the causality could reflect supply shocks and financial crises producing both a recession and subsequent stagnation. Meanwhile, Cerra and Saxena (2017) argue that recessions always have negative permanent effects on the level of aggregate output and question the relevance of the concept of an output gap in the first place, including in explaining weak economic activity and sluggish growth following the global financial crisis.

A contrasting view of secular stagnation, emphasized by Gordon (2015, 2016), is that it reflects supply-side forces such as slower productivity growth and demographic changes that started before the Great Recession. Notably, Fernald et al. (2017) use a growth accounting decomposition and find that, once allowing for cyclical effects, the slow growth in the U.S. economy since the Great Recession can be related to slow growth of total factor productivity and a decline in labor force participation, with both phenomena starting prior to the onset of the recession and not obviously connected to the financial crisis. Supporting this view, a few recent empirical studies have estimated a structural break in U.S. trend growth in the mid 2000s prior to the Great Recession, including Grant and Chan (2017), Antolin-Diaz, Drechsel and Petrella (2017), and Kamber, Morley and Wong (2018). However, an ability to reject that the slowdown actually occurred during the Great Recession, not before, is unclear 
from this literature.

In this paper, we develop a flexible new nonlinear time series model that allows us to examine the empirical support for competing views surrounding why U.S. real GDP did not return to its projected path prior to the Great Recession. In particular, we investigate whether this stagnation was due to level and growth hysteresis effects from the Great Recession, a persistent negative output gap following the recession, or slower trend growth for other reasons. Building on Hamilton (1989), Kim and Nelson (1999a), Kim, Morley and Piger (2005), and Eo and Kim (2016), our univariate Markov-switching model of real GDP growth allows a given recession to either permanently alter the level of aggregate output (an 'L-shaped' recession) or only have a temporary effect (a 'U-shaped' recession). ${ }^{1}$ We also account for structural change in trend growth. In particular, using the testing procedures from Qu and Perron (2007), we find an estimated reduction in the long-run growth rate of U.S. real GDP in 2006Q1. When allowing for this break in our Markov-switching model, we find that the Great Recession was U shaped, generating a negative and persistent output gap rather than any substantial level hysteresis effects, with the economy eventually recovering to a lower-growth trend path. However, our finding about the nature of the Great Recession is robust to the reduction in trend growth occurring earlier, allowing for more complicated patterns of structural change, or even assuming no structural change, although the model without a break in trend growth produces persistently downward biased forecast errors after the Great Recession. Compared to the analysis using Qu and Perron (2007) procedures, the precision of our inference that the break occurred before the Great Recession is sharpened considerably by taking into account nonlinear dynamics with our Markov-switching model. Notably, we are able to formally reject that the slowdown in trend growth occurred after 2006Q2 and, therefore, does not appear to be due to the Great Recession. Furthermore, we find that the apparent timing of the slowdown is more consistent with a reduction in productivity growth than demographic factors.

Our analysis is related to Huang, Luo and Startz (2016), who also consider a univariate

\footnotetext{
${ }^{1}$ The univariate approach often taken in the literature on nonlinear output growth dynamics makes the implicit simplifying assumption of a common propagation for all underlying symmetric shocks to aggregate output, regardless of their source. However, it has the benefit of allowing for a tightly parameterized, but still sophisticated specification of dynamics for asymmetric shocks, in our case allowing for different dynamics for two types of recessions.
} 
time series model with two different types of recessions, but determine the prevailing regime using NBER dates and assume a given recession is predetermined as being either $\mathrm{L}$ or $\mathrm{U}$ shaped. Our Markov-switching model is more directly an extension of Hamilton (1989), Kim and Nelson (1999a), and Kim, Morley and Piger (2005) to allowing two different types of recessions by modeling regimes as being stochastic. We believe this is a more natural assumption given that the exact timing and nature of recessions is not predetermined in practice. This also leads to a different result than Huang, Luo and Startz (2016) in terms of categorizing the Great Recession as being $U$ shaped rather than L shaped. Our model is also somewhat related to Kim and Murray (2002), Kim and Piger (2002), and Kim, Piger and Startz (2007), who consider multivariate unobserved components models with Markov-switching in both the trends and cycles of panels of macroeconomic time series, thus allowing for L- and U-shaped recessions. However, those models make assumptions about the correlations between permanent and transitory movements which implicitly place strong restrictions on the variance of the stochastic trend in aggregate output that do not appear to be supported by the data (Morley, Nelson and Zivot, 2003).

The rest of this paper proceeds as follows: In Section 2, we provide background evidence for nonlinearity and structural breaks in U.S. real GDP. In Section 3, we present the details of our new Markov-switching model and show how it can generate both L- and U-shaped recessions. In Section 4, we report estimates for a benchmark version of our model and examine implications for why real GDP has stagnated since the Great Recession. In Section 5 , we consider alternatives to our benchmark model in order to investigate the robustness and interpretation of our results. Section 6 concludes.

\section{Background}

There is some existing evidence for Markov-switching nonlinear dynamics in U.S. real GDP growth. Specifically, Morley and Piger (2012) test for nonlinearity using the procedure developed in Carrasco, Hu and Ploberger (2014) and find support for the Markov-switching model in Kim, Morley and Piger (2005) that captures U-shaped recessions, but not for the model in Hamilton (1989) that captures L-shaped recessions. However, the tests are applied 
using data over the sample period of 1947-2006 and so do not include the Great Recession. More recently, Morley and Panovska (2019) conduct tests for nonlinearity using data for a number of countries and find similar results to Morley and Piger (2012) of greater support for a Markov-switching model with U-shaped recessions than L-shaped recessions. For the U.S. data, they find support for nonlinearity when allowing for an estimated slowdown in trend growth in 2000Q2 based on Bai and Perron $(1998,2003)$ testing procedures. ${ }^{2}$ While it is not straightforward to apply the Carrasco, $\mathrm{Hu}$ and Ploberger (2014) testing procedure to our model, we note that Eo and Kim (2016) are able to reject simpler models with only one type of recession in favour of more heterogeneity in business cycle regimes using Bayesian methods, providing a strong motivation for allowing for two types of recessions. Furthermore, we are able to show that the estimated nonlinear dynamics capturing recessions for our model hold up well with more years of data, including enough observations after the end of the Great Recession to discriminate between competing hypotheses about its long-run consequences.

Before presenting the details of our new Markov-switching model, we follow Morley and Panovska (2019) by first considering possible structural breaks in trend growth in a nonparametric setting. We do so by applying Qu and Perron (2007) testing procedures for multiple structural breaks in mean and/or variance of quarterly U.S. real GDP growth for the sample period of 1947Q2 to 2018Q4 with 10\% trimming at the beginning and the end of the sample and between breakdates. ${ }^{3}$ The test regression for output growth includes only a constant, but we allow for serial correlation, such as would be implied by our Markov-switching model, in calculating test statistics by employing the Andrews-Monahan heteroskedasticity and autocorrelation consistent estimator of the long-run variance. Based on a likelihood ratio test, we find evidence of two breaks, which are estimated to have occurred in 1984Q2 and 2006Q1, respectively, as reported in Table 1. These breakdates align with the timing of

\footnotetext{
${ }^{2}$ Given the sample period of 1947-2016 and a minimum length 'trimming' restriction for subsamples of $15 \%$ of the total sample when testing for structural breaks, we note that Morley and Panovska (2019) are not able to consider whether the estimated breakdate corresponds to the Great Recession, while we are able to do so given the availability of a few extra years of data and our different choice of $10 \%$ trimming. Also, Bai and Perron $(1998,2003)$ procedures only allow for a break in mean, but not variance, unlike the Qu and Perron (2007) procedures considered in our analysis. Reporting the breakdate in Morley and Panovska (2019) as 2000Q2 corresponds to the convention of a breakdate being the last period of the previous structural regime.

${ }^{3}$ The raw data for seasonally-adjusted quarterly U.S. real GDP and all other series considered in this paper were obtained from the St. Louis Fed database (FRED) and quarterly growth rates were calculated as 100 times the first differences of the natural logarithms of the levels data.
} 
Table 1: Sequential structural break tests for output growth

\begin{tabular}{cccc}
\hline \# of Breaks & Test Statistic & $5 \%$ Critical Value & Estimated Breakdate(s) \\
\hline 1 & 72.87 & 12.80 & $1984 \mathrm{Q} 2$ \\
2 & 18.76 & 13.96 & $1984 \mathrm{Q} 2,2006 \mathrm{Q} 1$ \\
3 & 8.77 & 14.84 & 1984Q2, 2000Q2, 2009Q2 \\
\hline
\end{tabular}

Note: Critical values are from Qu and Perron (2007).

the Great Moderation widely reported in the literature (Kim and Nelson, 1999b; McConnell and Perez-Quiros, 2000) and the breakdate for the slowdown in trend growth that was also found in Kamber, Morley and Wong (2018). ${ }^{4}$ The structural breaks are significant at the $5 \%$ level and there is no support for an additional break even at a 10\% level. Related to the Great Moderation and our Markov-switching model, we note that a larger variance for output growth before 1984Q2 could potentially be related to a more frequent realization of recessions before the mid-1980s. In particular, the postwar U.S. economy experienced eight recessions between 1947 to 1984 (37 years), but only three recessions between 1985 to 2018 (34 years). Thus, we will be able to use our Markov-switching model to check whether this estimated structural break is due to the less frequent realization of recessions since 1984 or a reduction in residual volatility.

Table 2 reports estimates for the mean and standard deviation of output growth based on the estimated breakdates, along with the confidence sets for the breakdates. The confidence set for the first breakdate covers a reasonably short interval of 1982Q1 to 1987Q1, while the confidence set for the second breakdate is wider and ranges from 1991Q3 to 2011Q3, where the latter date represents the last possible breakdate given $10 \%$ trimming. The estimated breakdate of 2006Q1 is consistent with the date for the growth slowdown in Fernald et al. (2017) and they argue that it reflects slow growth of total factor productivity and a decline in labor force participation that are unrelated to the financial crisis and the Great Recession.

For the first estimated break in $1984 \mathrm{Q} 2$, a likelihood ratio test of no change in mean suggests that the break corresponded to a change in variance only, with the sample standard

\footnotetext{
${ }^{4} \mathrm{~A}$ break in 2006Q1 was also found in Luo and Startz (2014) for Bayesian estimation of an unobserved components model of U.S. real GDP. However, Kim and Chon (2020) show that the results for such a model are more favorable for gradual structural change when the posterior sampler for Bayesian estimation correctly takes correlation between movements in trend and cycle into account.
} 
Table 2: Mean and standard deviation of output growth given two structural breaks

\begin{tabular}{ccccc}
\hline Subsample & Mean & Std. Dev. & Estimated Breakdate & Confidence Set for Breakdate \\
\hline 1 & 0.89 & 1.16 & & \\
2 & 0.80 & 0.49 & $1984 \mathrm{Q} 2$ & {$[1982 \mathrm{Q} 1,1987 \mathrm{Q} 1]$} \\
3 & 0.41 & 0.59 & 2006Q1 & [1991Q3,2011Q3] \\
\hline
\end{tabular}

Note: Confidence sets are from inverted likelihood ratio approach in Eo and Morley (2015).

deviation of output growth dropping by more than $50 \%$. The average growth rates before and after the first estimated breakdate of 1984Q2 are very close to each other at 0.89 and 0.80 , respectively, by contrast to the average growth rate of 0.41 after the second breakdate of 2006Q1. We note that the decline in average growth since 2006Q1 could be related to the realization of a particularly severe recession between 2007-2009. Thus, we will also use our Markov-switching model to check whether this estimated structural break is due to the Great Recession or a more sustained decline in trend growth. Related, we will determine whether explicitly accounting for nonlinear dynamics affects the precision of inferences about the timing of structural breaks.

\section{Model}

We develop a new univariate Markov-switching model of real GDP growth that accommodates two different types of recessions. In particular, the model builds on the Markovswitching models in Hamilton (1989) and Kim, Morley and Piger (2005) which assume all recessions have the same dynamics by allowing for two distinct contractionary regimes: (i) an L-shaped regime with permanent effects on the level of output, as in Hamilton (1989), and (ii) a U-shaped regime with temporary effects, corresponding to a restricted version of the model in Kim, Morley and Piger (2005) that is related to Kim and Nelson (1999a). The idea of allowing for different contractionary regimes is strongly motivated by Eo and Kim (2016), who find a Markov-switching model with time-varying regime-dependent mean growth rates that depend on each other across booms and recessions fits the U.S. data better than the simpler Markov-switching models in Hamilton (1989) and Kim, Morley and Piger (2005).

Extending the specification in Kim, Morley and Piger (2005), we assume that output 
growth, $\Delta y_{t}$, has the following time-varying mean based on three regimes:

$$
\Delta y_{t}=\mu_{0}+\mu_{1} \cdot \mathbf{1}\left(S_{t}=1\right)+\mu_{2} \cdot \mathbf{1}\left(S_{t}=2\right)+\lambda_{2} \cdot \sum_{k=1}^{m} \mathbf{1}\left(S_{t-k}=2\right)+e_{t},
$$

where $\mathbf{1}(\cdot)$ is an indicator function, $S_{t}$ is a latent Markov-switching state variable that takes on discrete values such that $S_{t}=0$ for the expansionary regime, $S_{t}=1$ for the L-shaped contractionary regime, and $S_{t}=2$ for the U-shaped contractionary regime according to transition probabilities $\operatorname{Pr}\left[S_{t}=j \mid S_{t-1}=i\right]=p_{i j}$ for $i, j=0,1,2$, and $e_{t} \sim N\left(0, \sigma^{2}\right)$. For simplicity and following the empirical results in Hamilton (1989), Kim, Morley and Piger (2005), Morley and Piger (2012), Eo and Kim (2016), we abstract from autoregressive dynamics in linear shocks by assuming that $e_{t}$ is serially uncorrelated. ${ }^{5}$

To identify the contractionary regimes as corresponding to two different types of recessions, we assume that the economy does not switch between contractionary regimes without going through an expansionary regime first. This sequencing of regimes is imposed using the following restrictions on the regime transition probabilities: $p_{12}=0$ and $p_{21}=0$. Meanwhile, the $\lambda_{2}$ parameter is the key distinctive feature of the U-shaped contractionary regime in (1) because it allows for a bounceback effect that generates an asymmetric output gap, as in Kim, Morley and Piger (2005); Morley and Piger (2012); Morley and Panovska (2019). ${ }^{6}$ To clearly identify this regime as distinct from the L-shaped regime that only has permanent effects on the level of output by construction, we impose the restriction $\mu_{2}+m \cdot \lambda_{2}=0$. $^{7}$ This restriction implies that, following the realization of $S_{t}=2$, the bounceback effect $m \cdot \lambda_{2}$ exactly cancels out the contractionary effect from $\mu_{2}$ such that the U-shaped regime only

\footnotetext{
${ }^{5}$ Specifically, these earlier papers find that linear autoregressive dynamics in the residual are not particularly important once allowing for a Markov-switching mean. However, it is important to note that the statistical evidence for Markov-switching nonlinearity discussed in Section 2 allows for AR(2) dynamics in output growth under the null of linearity.

${ }^{6}$ Possible sources of an asymmetric output gap are capacity constraints, monopoly power, asymmetric wage and price adjustments, collateral constraints, aggregation of microeconomic shocks, and underlying asymmetric shocks. See Friedman (1964, 1993); DeLong and Summers (1988); Auroba, Bocola and Schorfheide (2013); Guerrieri and Iacoviello (2016); Baqaee and Farhi (2019); Dupraz, Nakamura and Steinsson (2019), among many others, for more information on these theories of business cycle asymmetry. Also see Morley $(2009,2019)$ for surveys of the broader literature on business cycle asymmetry.

${ }^{7}$ Typically with Markov-switching models, it is necessary to place labelling restriction such as $\mu_{1}<0$ and $\mu_{2}<0$ to identify the model. However, because there is no bounceback effect when $S_{t} \neq 2$, the three regimes turn out to be uniquely identified given the restriction on $\lambda_{2}$ and the restrictions on the transition probabilities. Thus, we place no restrictions on the other parameters in (1).
} 
has temporary effects on the level of output, as in the Markov-switching model in Kim and Nelson (1999a), but distinct from the model in Kim, Morley and Piger (2005), which does not impose this restriction. ${ }^{8}$

Figure 1 illustrates how the two contractionary regimes create different types of recessions in terms of their long-run effects on the level of output. In particular, we plot the path of output implied by the model in (1) before, during, and after the occurrence of a contractionary regime. Motivated by the estimates for our benchmark model presented in the next section, we set the length of the post-recession bounceback effect to $m=5$ quarters and the model parameters to be $\mu_{0}=0.91$ for the expansionary regime, $\mu_{1}=-1.32$ for the L-shaped regime, and $\mu_{2}=-2.10$ for the U-shaped regime (thus, implying $\lambda_{2}=0.42$ ). For clarity in seeing the relative impact of the two different regimes, we abstract from the linear $e_{t}$ shocks when calculating the path of output. We assume that the economy enters a contractionary regime at time $t=0$ that lasts for 4 quarters for the L-shaped regime and 5 quarters for the U-shaped regime. The longer duration for the U-shaped regime is motivated by a higher continuation probability in the next section. However, because the bounceback effect takes hold as the U-shaped regime persists and flattens out the path of output, there is only an outright recession in the level of output for 4 quarters in both cases. After the flat path for output for the one additional quarter of the U-shaped regime, the economy grows quickly and eventually recovers to its pre-recession path. In this sense, the recession has no permanent effect on the level of output and its path traces out what looks like a tilted and elongated "U". By contrast, for the L-shaped regime, the absence of a bounceback effect means that the economy contracts sharply in the recession and never recovers to its pre-recession path, but only grows at the usual expansionary rate when the recession is over. Thus, this recession has a permanent effect on the level of output and its path traces out what looks like a tilted "L".

\footnotetext{
${ }^{8}$ In addition to our consideration of a latent Markov-switching state variable instead of predetermined NBER dates, this restriction on the bounceback effect is another key distinction from Huang, Luo and Startz (2016), who allow for possible permanent effects with their U-shaped regime, as in Kim, Morley and Piger (2005), in addition to assuming permanent effects with their L-shaped regime.
} 
Figure 1: Illustration of different types of recessions

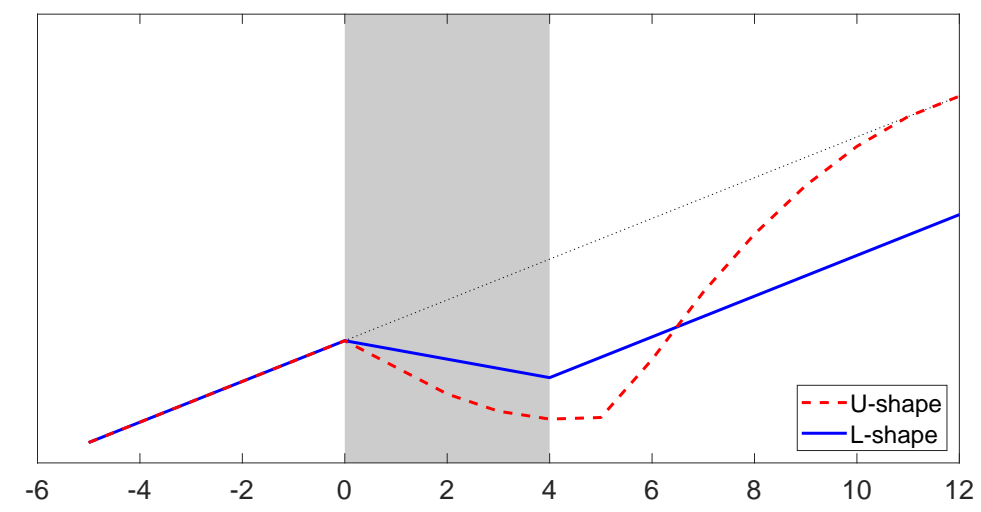

Note: The shaded area denotes the contractionary regime.

\section{Benchmark Results}

Estimation is conducted via maximum likelihood, where the conditional likelihood function given the length of the post-recession bounceback effect $m$ is evaluated based on the filter presented in Hamilton (1989) keeping track of $3^{m+1}$ states in each period. The estimate of the discrete-value parameter $m$ is also chosen to maximize the likelihood by considering the profile likelihood for $m$ across a set of different possible values (capped at $m=7$, corresponding to 6,561 possible states to keep track of in estimation, for computational feasibility). Note that, because the estimates of the other parameters are based on the conditional likelihood function, reported standard errors based on numerical second derivatives do not reflect sampling uncertainty about $\hat{m}$.

To incorporate the possible structural breaks found in Section 2 into the benchmark version of our model, we modify the basic model in (1) as follows:

$$
\Delta y_{t}=\mu_{0}+\delta \cdot \mathbf{1}(t>\tau)+\mu_{1} \cdot \mathbf{1}\left(S_{t}=1\right)+\mu_{2} \cdot \mathbf{1}\left(S_{t}=2\right)+\lambda_{2} \cdot \sum_{k=1}^{m} \mathbf{1}\left(S_{t-k}=2\right)+e_{t},
$$

where $e_{t} \sim N\left(0, \sigma_{t}^{2}\right)$, with $\sigma_{t}^{2}=\sigma_{v 0}^{2} \cdot \mathbf{1}\left(t \leq \tau_{v}\right)+\sigma_{v 1}^{2} \cdot \mathbf{1}\left(t>\tau_{v}\right)$. Based on the findings in Section 2, we assume the breakdates $\tau=2006 \mathrm{Q} 1$ for trend growth and $\tau_{v}=1984 \mathrm{Q} 2$ for residual volatility in our benchmark model. If the breaks found in Section 2 actually reflected the severe recession in 2007-09 and the less frequent realization of recessions in the 
Table 3: Parameter estimates for the benchmark model

\begin{tabular}{lcc}
\hline Parameter & Estimate & Standard Error \\
\hline$p_{01}$ & 0.03 & 0.01 \\
$p_{02}$ & 0.02 & 0.01 \\
$p_{11}$ & 0.66 & 0.17 \\
$p_{22}$ & 0.73 & 0.13 \\
$\mu_{0}$ & 0.91 & 0.05 \\
$\mu_{1}$ & -1.32 & 0.27 \\
$\mu_{2}$ & -2.10 & 0.29 \\
$\lambda_{2}$ & 0.42 & 0.06 \\
$\delta$ & -0.41 & 0.08 \\
$\sigma_{v 0}$ & 0.90 & 0.07 \\
$\sigma_{v 1}$ & 0.42 & 0.03 \\
$m$ & 5 & \\
$\log -\operatorname{lik}$ & -317.35 & \\
\hline
\end{tabular}

Notes: The benchmark model is given by (2) with $\tau=2006 \mathrm{Q} 1$, and $\tau_{v}=1984 \mathrm{Q} 2$.

second half of the sample period, then the estimate for $\delta$ should be small and $\sigma_{v 1}^{2}$ should be similar to $\sigma_{v 0}^{2}$. However, incorporating these structural breaks allows for a permanent trend growth slowdown and a reduction in the volatility of linear shocks in the second half of the sample period if these phenomena remain relevant even when accounting for Markovswitching dynamics.

Table 3 reports maximum likelihood estimates for the benchmark model. The implied growth rates $\hat{\mu}_{0}+\hat{\mu}_{1}<0$ for the L-shaped regime and $\hat{\mu}_{0}+\hat{\mu}_{2}<0$ for the $\mathrm{U}$-shaped regime, indicating that both regimes are indeed contractionary, even though this was not imposed in estimation. The estimated transition probabilities suggest that expansions are much more persistent than either type of recessions, like the NBER reference cycle. In particular, the implied continuation probability of the expansionary regime $1-\hat{p}_{01}-\hat{p}_{02}$ is 0.96 , with expected duration of 23 quarters, while the expected duration is 3 quarters for the L-shaped regime and 4 quarters for the U-shaped regime. Residual volatility is estimated to have dropped by more than half in 1984Q2, suggesting the Great Moderation was not simply due to less frequent realization of recessions. Meanwhile, the estimated reduction in trend growth in 2006Q1 of -0.41 is very close to the reduction of -0.39 found with the $\mathrm{Qu}$ and Perron (2007) analysis in Section 2, suggesting that lower average growth since 2006 was also not simply due to the realization of a severe recession. The estimated length of the post-recession 
Figure 2: Implied time-varying mean and quarterly output growth

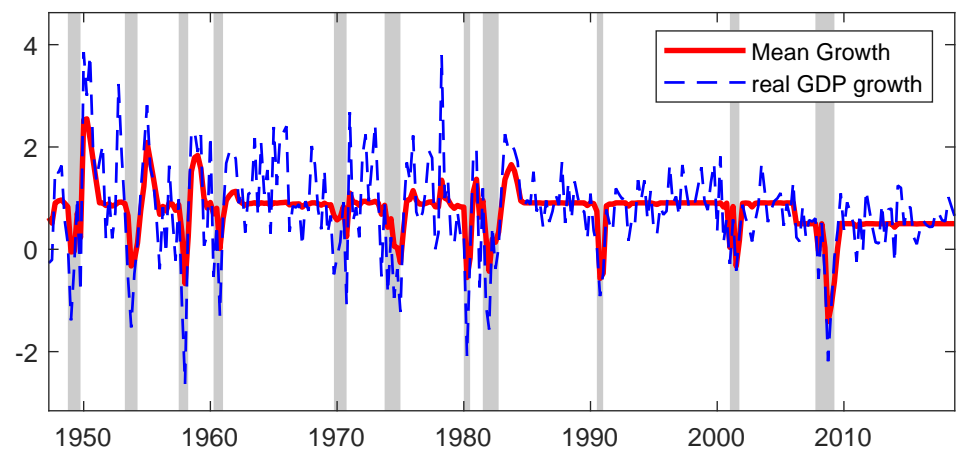

Note: The shaded areas denote NBER recession dates.

bounceback effect is 5 quarters, although we note that other parameter estimates are very similar for $m=6$, which was the length considered in Kim, Morley and Piger (2005). ${ }^{9}$

Figure 2 plots the implied time-varying mean from the benchmark model using the filtered estimate $E\left[\mu_{t} \mid \Omega_{t}\right]$, where $\mu_{t} \equiv \Delta y_{t}-e_{t}$ and $\Omega_{t} \equiv\left(\Delta y_{1}, \Delta y_{2}, \ldots, \Delta y_{t}\right)$. Closely tracking realized real GDP growth and reflecting $\hat{\delta}=-0.41$, the time-varying mean declines abruptly after 2006Q1, with this slowdown in trend growth explaining the weak recovery of the U.S. economy following the Great Recession. ${ }^{10}$ It is also clear from the figure that not accounting for a break in trend growth in 2006Q1 would have resulted in persistently downward biased forecast errors even after the Great Recession.

To help illustrate the magnitude of the trend break in 2006Q1, Figure 3 plots projections from $t=2006 \mathrm{Q} 1$ for future log output $E\left[y_{t+h} \mid \Omega_{t}\right], h>0$, both accounting for and not accounting for the structural break. The black dotted line shows the projection of $\log$ output without accounting for the structural break, which diverges markedly from realized log output (solid blue line) even before the Great Recession. The red dashed line shows the projection accounting for the structural break and clearly supports the idea that the decline in trend growth began in 2006 prior to the onset of the Great Recession. Notably, given the natural $\log$ scale, the difference by the end of the Great Recession corresponds to more than

\footnotetext{
${ }^{9}$ For comparison, the log-likelihood values for $m=4,6,7$ are $-318.59,-317.65$, and -318.68 , respectively.

${ }^{10}$ Figure 2 looks similar to the estimated time-varying mean in Eo and Kim (2016) for a Markov-switching model with time-varying regime-dependent mean growth rates that depend on each other across booms and recessions and also allowing for possible structural change in trend growth. Our relatively simple model captures differences in mean growth for each recession and expansion based on whether the contractionary regime is $\mathrm{L}$ or $\mathrm{U}$ shaped, with mean growth in a recession related to mean growth in the subsequent expansion.
} 
Figure 3: Projected and realized log output

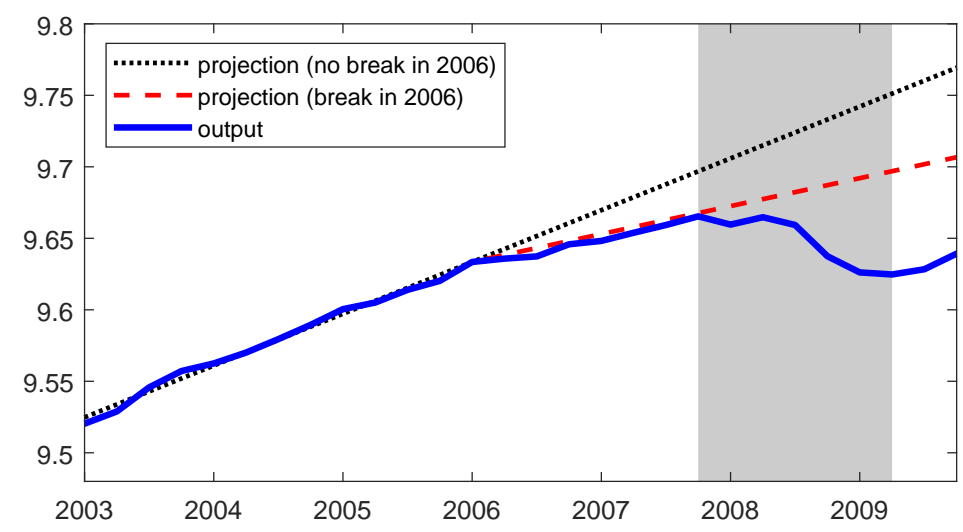

Notes: The shaded area denotes the Great Recession.

$5 \%$ of the level of real GDP in 2006Q1.

Figure 4 reports the smoothed probabilities of being in a contractionary regime in period $t$. The left panel plots the probability of being in one or the other regime, calculated from the sum of the probabilities of being in the L-shaped regime and the U-shaped regime using $\operatorname{Pr}\left[t=\right.$ contraction $\left.\mid \Omega_{T}\right] \equiv \operatorname{Pr}\left[S_{t}=1 \mid \Omega_{T}\right]+\operatorname{Pr}\left[S_{t}=2 \mid \Omega_{T}\right]$. This probability closely matches the timing of NBER recessions. In particular, for nine of the eleven NBER recessions in the sample, the smoothed probability is well above $50 \%$ for most of a given recession. The right panel of Figure 4 plots the underlying smoothed probabilities of the L-shaped and U-shaped regimes. Considering their relative contribution to the overall probability of a contractionary regime, these probabilities suggest that the 1973-75, 1990-91, and 2001 recessions in particular can be classified as L shaped, while the 2007-09 recession can be largely classified as U shaped, with only the small probability of an L-shaped regime at the beginning of the recession implying any level hysteresis effects. The less definitive classification of the other recessions suggests they may exhibit more of a partial recovery, as found for the estimated bounceback model in Kim, Morley and Piger (2005).

It might seem surprising that the Great Recession is classified as being $U$ shaped given the conventional view that recessions associated with financial crises have large permanent effects on the level of economic activity. ${ }^{11}$ Also, mean growth in Figure 2 does not display the

\footnotetext{
${ }^{11}$ See, for example, Cerra and Saxena (2008), Reinhart and Rogoff (2009), and Jordà, Schularick and Taylor (2017).
} 
Figure 4: Smoothed probabilities of contractionary regimes

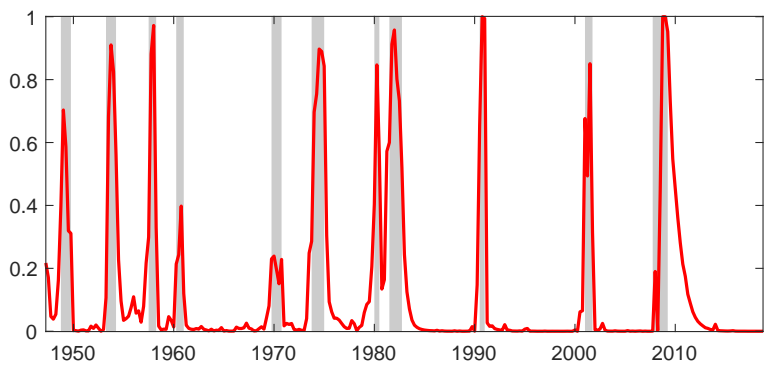

(a) Probability of a contractionary regime

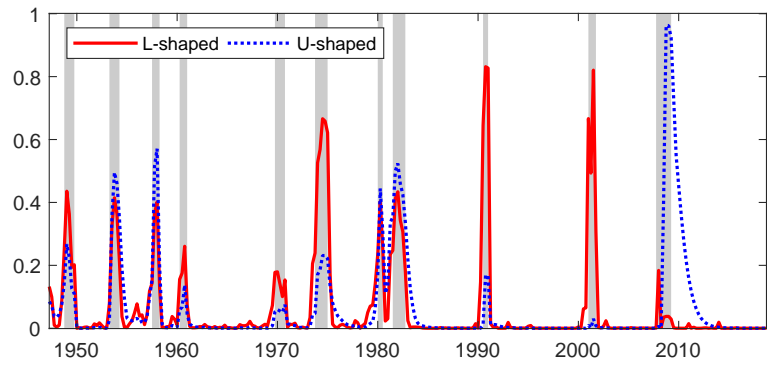

(b) Probabilities of L-shaped and U-shaped regimes

Note: The shaded areas denote NBER recession dates.

same surge after the Great Recession as occurred following other recessions with a sizeable probability of being $U$ shaped. The econometric explanation for this finding is that the probability corresponding to a U-shaped regime in Figure 4 remains elevated for a substantial period of time after the trough date established by the NBER for the Great Recession. ${ }^{12}$ This could be related to a prolonged weak labor market ('jobless recovery') following the recession. Also, the zero-lower-bound on interest rates restricted the ability of monetary policy to help stimulate a strong recovery immediately after the recession. Thus, the relatively tame mean growth following the Great Recession could be related to a large persistent negative output gap that only dissipates very slowly.

To estimate the output gap implied by our model, we adopt the regime-dependent steadystate (RDSS) generalization of the Beveridge and Nelson (1981) decomposition for Markovswitching processes developed in Morley and Piger (2008). This approach involves constructing long-horizon forecasts conditional on sequences of regimes and then marginalizing over the distribution of the unknown regimes. Unlike the traditional Beveridge-Nelson decomposition, there is no implicit assumption that the cycle is unconditionally mean zero and we choose the expansionary regime as having a mean-zero transitory component. ${ }^{13}$

Figure 5 plots the estimated output gap from the RDSS decomposition implied by the benchmark model. The large negative movements in the output gap closely match up with

\footnotetext{
${ }^{12}$ As illustrated in Figure 1 in the previous section, a U-shaped regime can imply flat growth after the end of a recession if the regime persists long enough before the eventual recovery to the pre-recession path.

${ }^{13}$ See Morley and Piger (2008) for a full discussion of this choice and Morley and Piger (2012) for a justification of choosing the expansionary regime as having a mean-zero transitory component.
} 
Figure 5: Estimated output gap

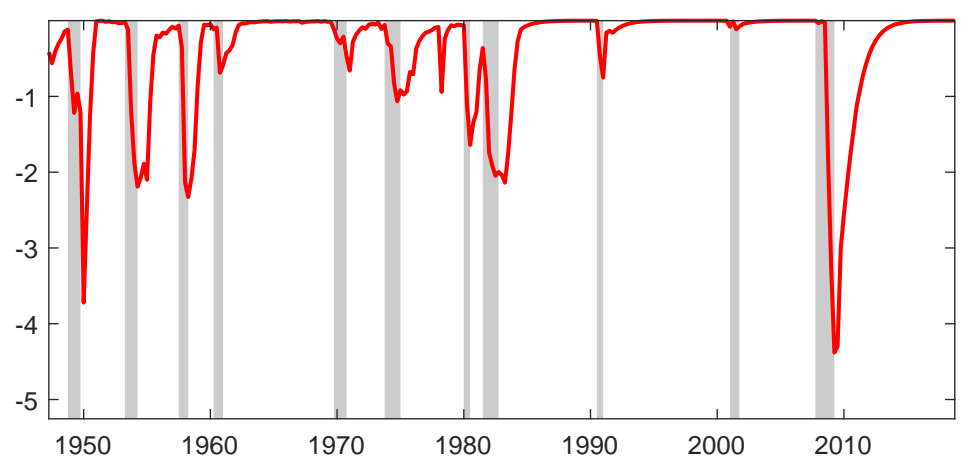

Note: The shaded areas denote NBER recession dates.

some of the NBER-dated recessions. However, because an L-shaped contractionary regime is assumed to only affect the trend, the large negative movements in the output gap correspond primarily to the recessions with a high probability of being $U$ shaped. In terms of the Great Recession, the negative output gap opens up later than the NBER peak date of 2007Q4, corresponding to when the probability of U-shaped regime spikes up in Figures 4. As Figure 3 makes clear, the reason for this different timing is that the level of real GDP does not decline sharply until the second half of 2008, although real GDP did not grow at its usual expansionary rate in the first half of 2008, even accounting for the structural break in trend growth. This delayed timing of the severe contraction for the Great Recession is distinct from the behavior of real GDP in previous recessions and could perhaps reflect a misattribution by the NBER of a particularly lackluster manifestation of weak trend growth during the first half of 2008 as being part of the recession phase. ${ }^{14}$ Meanwhile, the output gap remains persistently negative long after the NBER trough date, corresponding to only a very slow recovery in the level of output.

Figure 6 plots log output and estimated trend from the RDSS decomposition around the Great Recession. The magnitude and persistence of the output gap following the recession is clear from this figure. In particular, the implied negative output gap is not estimated to fully close until around 2012. Because the closure of the output gap is so slow, there is no apparent surge in output growth following the recession in Figure 2. However, it is

\footnotetext{
${ }^{14}$ Instead, the weak growth may be related to a typical end-of-expansion overhiring phenomenon (Gordon, 2003) that lowered productivity prior to the full-blown recession in the second half of 2008.
} 
Figure 6: Output and trend around the Great Recession

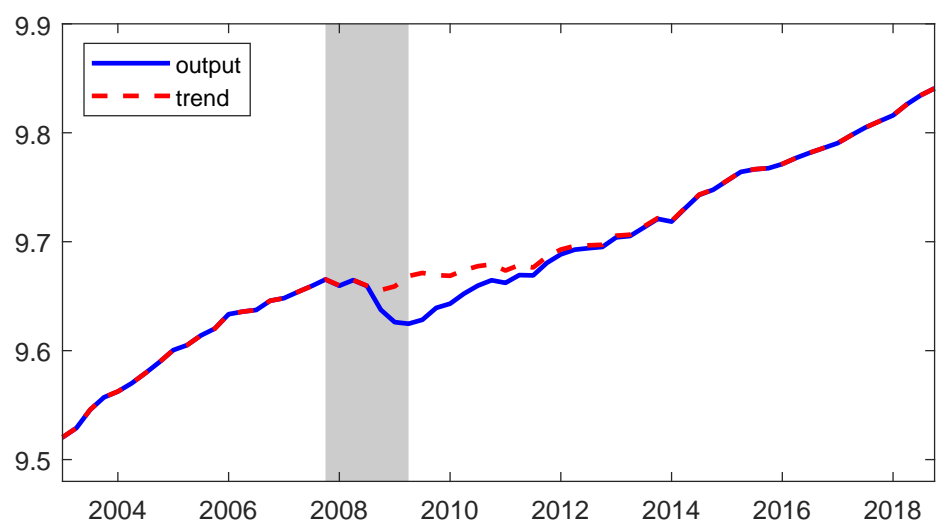

Note: The shaded area denotes the Great Recession.

important to note that this estimated dynamic of a persistent negative output gap is clearly distinctly identified from an L-shaped recession that only alters the level of trend output. If we consider a modification of our model to impose that the Great Recession was L shaped and not U shaped, such as was found in Huang, Luo and Startz (2016) using NBER dates for the regimes, the fit of the model noticeably deteriorates, with the log-likelihood dropping to -319.61 from -317.35 for our benchmark model. ${ }^{15}$ The deterioration of fit appears to be due to a failure to capture the rounded $U$ shape of the recession as it approaches its trough and an eventual gradual recovery of output to a trend path that are both evident in Figure 6.

\section{Robustness}

In this section, we consider some alternatives to our benchmark model in order to investigate the robustness and interpretation of our results. First, we estimate two models that allow us to consider whether there are really different types of recessions in terms of their permanent effects on the level of output. Second, we estimate a model using output per capita and examine the role of demographics in driving our results. Third, we directly estimate breakdates for the structural breaks in trend growth and residual volatility as additional

\footnotetext{
${ }^{15}$ To estimate a restricted model that imposes the Great Recession is an L-shaped regime, we set the parameters for the expansionary and U-shaped regimes to temporarily take on implausible values for the duration of the NBER dates corresponding to the Great Recession.
} 
parameters in the model rather than assuming the estimated breakdates from Section 2. Fourth, we check whether our inferences about the Great Recession are robust to alternative assumptions about the nature of structural change in trend growth and the length of the post-recession bounceback effect.

\subsection{Are there really two different types of recessions?}

To consider whether there are actually two different types of recessions, we estimate two alternative model specifications. The first model is more general than our benchmark specification in that it allows for a possible bounceback effect in the first contractionary regime in addition to the assumed full recovery in the second contractionary regime:

$$
\begin{aligned}
\Delta y_{t}=\mu_{0}+\delta \cdot \mathbf{1}(t>\tau) & +\mu_{1} \cdot \mathbf{1}\left(S_{t}=1\right)+\lambda_{1} \cdot \sum_{k=1}^{m} \mathbf{1}\left(S_{t-k}=1\right) \\
& +\mu_{2} \cdot \mathbf{1}\left(S_{t}=2\right)+\lambda_{2} \cdot \sum_{k=1}^{m} \mathbf{1}\left(S_{t-k}=2\right)+e_{t}
\end{aligned}
$$

where the possibility that $\lambda_{1} \neq 0$ makes the model more general than (2). Unlike $\lambda_{2}$, which is constrained such that $\mu_{2}+m \cdot \lambda_{2}=0$, we leave $\lambda_{1}$ unrestricted. Thus, the general model nests our benchmark model if $\hat{\lambda}_{1}=0$. In principle, it also nests the possibility that there are only U-shaped recessions with full recoveries if $\hat{\mu}_{1}=\hat{\mu}_{2}$ and $\hat{\lambda}_{1}=\hat{\lambda}_{2}$, although the regime transition probabilities would not be well identified in such a case. The second model is a restricted version of the general model in (3) with only one contractionary regime and corresponds to the original bounceback model in Kim, Morley and Piger (2005):

$$
\Delta y_{t}=\mu_{0}+\delta \cdot \mathbf{1}(t>\tau)+\mu_{1} \cdot \mathbf{1}\left(S_{t}=1\right)+\lambda_{1} \cdot \sum_{k=1}^{m} \mathbf{1}\left(S_{t-k}=1\right)+e_{t}
$$

where, again, we leave $\lambda_{1}$ unrestricted and we only need to estimate regime transition parameters $p_{01}$ and $p_{11}$. This restricted model nests the possibility that there are only L-shaped recessions if $\hat{\lambda}_{1}=0$. For both alternative models, $e_{t} \sim N\left(0, \sigma_{t}^{2}\right)$ is specified as in (2) to allow for a structural break in residual volatility. The breakdates are also the same as in the benchmark model: $\tau=$ 2006Q1 and $\tau_{v}=1984 \mathrm{Q} 2$. For direct comparability to our 
Table 4: Parameter estimates for alternative models

\begin{tabular}{lccccc}
\hline & \multicolumn{2}{c}{ General Model } & & \multicolumn{2}{c}{ Restricted Model } \\
\cline { 2 - 3 } \cline { 5 - 6 } Parameter & Estimate & S.E. & & Estimate & S.E. \\
\hline$p_{01}$ & 0.03 & 0.02 & & 0.05 & 0.02 \\
$p_{02}$ & 0.02 & 0.01 & & \\
$p_{11}$ & 0.68 & 0.14 & & 0.80 & 0.07 \\
$p_{22}$ & 0.73 & 0.13 & & \\
$\mu_{0}$ & 0.94 & 0.05 & & 0.94 & 0.05 \\
$\mu_{1}$ & -1.02 & 0.22 & & -1.24 & 0.15 \\
$\mu_{2}$ & -2.08 & 0.28 & & \\
$\lambda_{1}$ & -0.10 & 0.05 & & 0.12 & 0.04 \\
$\lambda_{2}$ & 0.42 & 0.06 & & \\
$\delta$ & -0.39 & 0.08 & & -0.48 & 0.08 \\
$\sigma_{v 0}$ & 0.90 & 0.07 & & 1.00 & 0.07 \\
$\sigma_{v 1}$ & 0.41 & 0.03 & & 0.43 & 0.03 \\
$\log -$ lik & -315.74 & & & -323.87 & \\
\hline
\end{tabular}

Note: The general model is given by (3) and restricted model by (4), both with $\tau=2006 \mathrm{Q} 1, \tau_{v}=1984 \mathrm{Q} 2$, and $m=5$.

benchmark model, we set $m=5$ rather than estimate it.

Table 4 reports maximum likelihood estimates for the two alternative models in (3) and (4). For the general model, the estimate for the additional parameter $\hat{\lambda}_{1}<0$, implying prolonged slow growth following an L-shaped recession rather than any bounceback effect. Given an offsetting smaller magnitude for $\hat{\mu}_{1}$ and other parameters similar to those in Table 3 , the implied dynamic effects of the two types of recessions are close to those in the benchmark model. ${ }^{16}$ Meanwhile, for the restricted model, the estimates imply only a partial recovery for all recessions given $\hat{\lambda}_{1}<-\hat{\mu}_{1} / 5$. The estimated expected partial recovery looks like an averaging of the estimated effects of the two contractionary regimes for the general model. Notably, the fit of the restricted model is considerably worse, although a likelihood ratio test of the two models would not have a standard distribution. Taken together, though, these results, combined with the different smoothed probabilities for the two regimes in Figure 4, support the idea of two different types of recessions in the U.S. economy.

\footnotetext{
${ }^{16}$ Note that, if we constrain $\lambda_{1} \geq 0$, the maximum likelihood estimate is exactly $\hat{\lambda}_{1}=0$.
} 
Table 5: Parameter estimates using output growth per capita

\begin{tabular}{lcc}
\hline Parameter & Estimate & S.E. \\
\hline$p_{01}$ & 0.03 & 0.01 \\
$p_{02}$ & 0.02 & 0.01 \\
$p_{11}$ & 0.75 & 0.09 \\
$p_{22}$ & 0.67 & 0.13 \\
$\mu_{0}$ & 0.64 & 0.04 \\
$\mu_{1}$ & -1.29 & 0.13 \\
$\mu_{2}$ & -2.09 & 0.22 \\
$\lambda_{2}$ & 0.42 & 0.06 \\
$\delta$ & -0.40 & 0.07 \\
$\sigma_{v 0}$ & 0.87 & 0.06 \\
$\sigma_{v 1}$ & 0.40 & 0.03 \\
$\log -$ lik & -313.69 & \\
\hline
\end{tabular}

Note: The model specification is the same as the benchmark case in (2) with $\tau=2006 \mathrm{Q} 1, \tau_{v}=1984 \mathrm{Q} 2$, and $m=5$.

\subsection{What is the role of demographics in the growth slowdown?}

We apply our benchmark model specification with two different types of recessions to output growth per capita instead of overall output growth in order to isolate the effects of population growth on overall trend output growth. Table 5 reports the estimates for this case. The estimates are strikingly similar to those for output growth presented in Table 3. One particularly notable similarity is that the slowdown in trend growth per capita is estimated to be $\hat{\delta}=-0.40$, which is very close to $\hat{\delta}=-0.41$ for the benchmark model. This directly implies that population growth is not responsible for the slowdown in overall trend output growth since 2006, but instead suggests possible roles for productivity and labor force participation (Stock and Watson, 2012; Fernald et al., 2017).

Figure 7 plots growth rates of intensive measures of output and related inputs. In particular, the top two panels show the growth rates of output per capita and per employed worker, while the bottom two panels show the growth rates of the employment-population ratio and the population growth rate. It is clear that there is an abrupt fall in the average level of the intensive output growth rates in 2006, while there is no obvious fall in the related input growth rates at the same time. Population growth does appear somewhat lower on 
Figure 7: Growth rates of intensive output and inputs

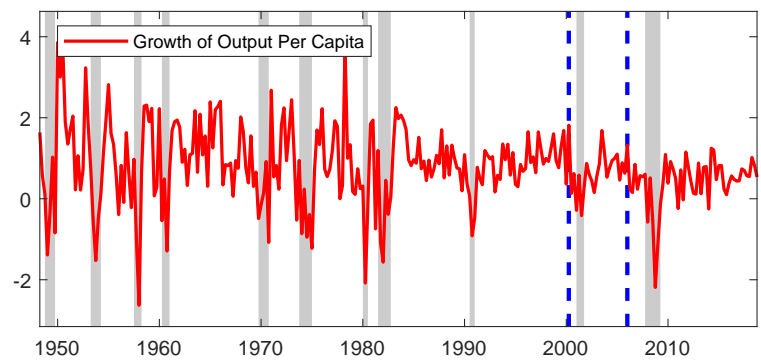

(a) Output per capita

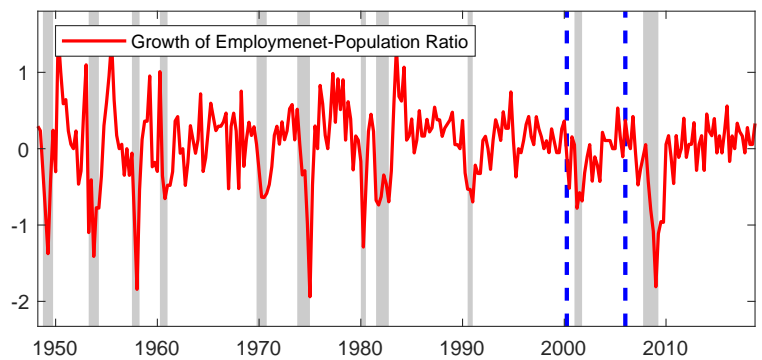

(c) Employment-population ratio

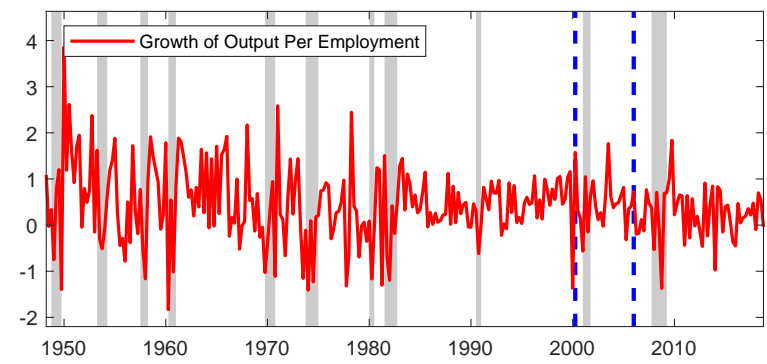

(b) Output per employed worker

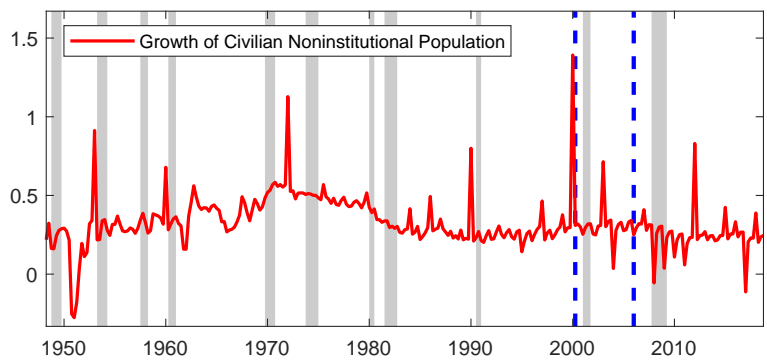

(d) Population

Notes: The dashed blue vertical lines indicate the dates of 2000Q2 and 2006Q1. The shaded areas denote NBER recession dates.

average from the onset of the Great Recession and growth of the employment-output ratio falls dramatically during the Great Recession, as it has done in other recessions. However, these changes in population growth and growth of the employment-output ratio cannot explain the estimated timing of a structural break in 2006 and the employment-output ratio growth rate seems to stabilize after the Great Recession. Thus, demographic factors such as population growth and labor force participation (at least assuming the unemployment rate is stationary) do not appear to be the main driver of a slowdown in overall trend output growth since 2006. Instead, given the slowdown is evident in intensive measures of output, changes in productivity growth would seem the more likely source of slow trend output growth.

Table 6 reports trend growth decompositions based on basic accounting relationships between the growth rates of output, output per capita, output per employed worker, the employment-population ratio, and population for both before and after a breakdate of 
Table 6: Trend growth decompositions

\begin{tabular}{llrrrrr}
\hline \multirow{3}{*}{ Model-implied trend growth } & & $\Delta \ln Y_{t}$ & $\Delta \ln \left(Y_{t} / N_{t}\right)$ & $\Delta \ln \left(Y_{t} / E_{t}\right)$ & $\Delta \ln \left(E_{t} / N_{t}\right)$ & $\Delta \ln N_{t}$ \\
\cline { 2 - 7 } & pre-2006 & 0.91 & 0.64 & 0.45 & 0.13 & \\
& post-2006 & 0.50 & 0.24 & 0.23 & 0.03 & \\
& Reduction & -0.41 & -0.40 & -0.22 & -0.10 & \\
& pre-2006 & 0.86 & 0.52 & 0.47 & 0.05 & 0.34 \\
& post-2006 & 0.41 & 0.16 & 0.23 & -0.08 & 0.25 \\
& Reduction & -0.45 & -0.36 & -0.24 & -0.12 & -0.09 \\
\hline
\end{tabular}

Note: Model-implied trend growth rates correspond to estimated growth in the expansionary regime in (2).

Unlike average growth rates, they do not necessarily add up exactly according to accounting relationships due to differences in estimated regimes for different variables.

2006Q1. ${ }^{17}$ We consider the estimated growth in an expansionary regime implied by our model estimated for the various growth rate series, as well as subsample averages for comparison. Corresponding to the results reported in Tables 3 and 5 and the visual impressions in Figure 7, a lot of the slowdown in overall trend growth can be explained by a reduction in the growth rate of output per capita rather than population growth. Indeed, in terms of estimates for our benchmark model, almost all of the slowdown is accounted for by a reduction in trend growth for output per capita. In terms of the estimates based on subsample averages, most of the slowdown is accounted for in the same way, although we note that the Great Recession has considerable influence on average growth rates since 2006 that is controlled for in our model-based estimates of trend growth. For output per capita growth, more of the slowdown can be explained by a reduction in the growth of output per employed worker than by a reduction in the growth of the employment-population ratio. Thus, these results confirm the impression from Figure 7 that productivity played a bigger role than demographics in explaining the slowdown in overall trend growth.

\footnotetext{
${ }^{17}$ The accounting relationships that inform our trend growth decompositions are $\Delta \ln Y_{t} \equiv \Delta \ln \left(Y_{t} / N_{t}\right)+$ $\Delta \ln N_{t}$ and $\Delta \ln Y_{t} \equiv \Delta \ln \left(Y_{t} / E_{t}\right)+\Delta \ln \left(E_{t} / N_{t}\right)+\Delta \ln N_{t}$, where $Y_{t}, N_{t}, E_{t}$ denote output, population, and employment, respectively.
} 


\subsection{What does our model imply about timing of structural breaks?}

In Section 2, we estimated breakdates of 1984Q2 and 2006Q1 for output volatility and trend growth, respectively, using Qu and Perron (2007) testing procedures. Based on this result, we assumed these breakdates as known parameters $\tau_{v}$ and $\tau$ when estimating the benchmark model in Section 4. Here, we examine whether inferences about structural breaks are robust to estimating their timing under the assumption that our Markov-switching model captures the dynamics of output growth.

Figure 8 plots profile likelihoods for the breakdates based on the Markov-switching model in (2). In particular, the left panel shows the results for the residual volatility breakdate $\tau_{v}$ and the right panel shows the results for the trend growth breakdate $\tau \cdot{ }^{18}$ The maximum likelihood estimate for the structural break in residual volatility is 1982Q2, which is close to the breakdate of 1984Q2 assumed in our benchmark model. The log likelihood value for the volatility breakdate of 1982Q2 is -315.28 compared to the value of -317.35 for the benchmark model with the breakdate in 1984Q2. The difference is less than the cutoff value used for constructing a 95\% confidence set for a breakdate in Eo and Morley (2015). Therefore, the confidence set for the volatility breakdate includes the benchmark assumption of 1984Q2 obtained from Qu and Perron (2007) procedures in Section 2. The maximum likelihood estimate for the structural break in trend growth of 2000Q2 is the same breakdate as found in Morley and Panovska (2019) using Bai and Perron $(1998,2003)$ testing procedures for a shorter sample period. However, 2006Q1 is a local mode for the profile likelihood and cannot be rejected using the cutoff value for constructing a $95 \%$ confidence set for a breakdate in Eo and Morley (2015). Furthermore, the last date in the 95\% confidence set is 2006Q2 and we find no support for an additional structural break in trend growth. Thus, compared to

\footnotetext{
${ }^{18}$ The profile likelihoods are calculated as log likelihood values for different possible breakdates, conditioning on the maximum likelihood estimate of a trend growth break in 2000Q2 in the case of $\tau_{v}$ and the maximum likelihood estimate of a residual volatility break in 1982Q2 in the case of $\tau$ and maximizing the other parameters out of the likelihood for each possible breakdate. We condition on the maximum likelihood estimate for the other breakdate for computational simplicity, although we have confirmed these are maximum likelihood estimates by calculating the likelihood for a grid of possible breakdates in residual volatility between 1979Q3 and 1987Q1 and breakdates in trend growth between 1997Q2 and 2012Q2. The profile likelihoods that maximize all other parameters including the other breakdate out of the likelihood (and assuming the conditional maximum likelihood estimate of the other breakdate is always in the included range) are almost identical to the profile likelihoods presented in Figure 8 for the sample ranges covered by the grid.
} 
Figure 8: Profile likelihoods for breakdates

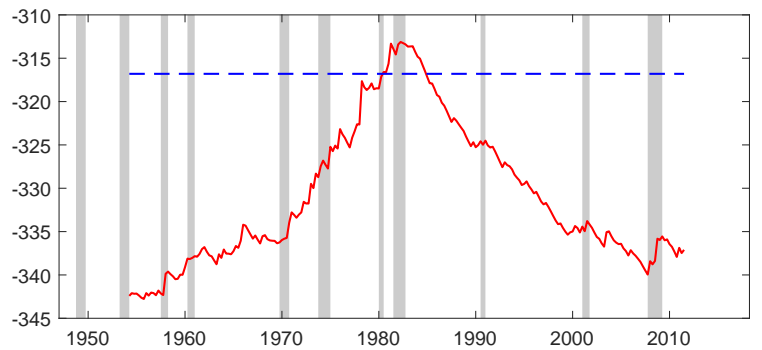

(a) Residual volatility breakdate $\tau_{v}$

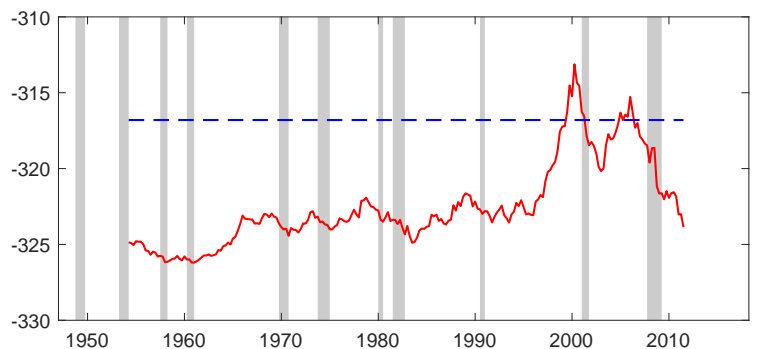

(b) Trend growth breakdate $\tau$

Notes: The red lines plot log likelihood values for different possible breakdates, conditioning on $\tau=2000 \mathrm{Q} 2$ for $\tau_{v}$ and $\tau_{v}=1982 \mathrm{Q} 2$ for $\tau$. The dashed blue horizontal lines correspond to cutoffs for $95 \%$ confidence sets based on a likelihood ratio test for a breakdate.

the results for the Qu and Perron (2007) procedures, our Markov-switching model sharpens inferences about the timing of a structural break in trend growth and allows us to formally reject that the trend growth slowdown occurred either during or after the Great Recession.

If the structural break in trend growth actually occurred in 2000Q2, as implied by the highest mode in the left panel of Figure 8, it is even clearer than with an estimate in 2006Q1 that it is unrelated to the Great Recession or the forces that led to the financial crisis. At the same time, it is possible that the spike in the likelihood in 2000Q2 is somehow related to overfitting the slow growth right before and during the 2001 recession. Looking back at Figure 2, it is possible to see how a trend growth slowdown could capture the weak output growth between 2000 and 2002 without having to capture the 2001 recession as being due to a contractionary regime shift. However, assuming a trend growth slowdown in 2000Q2 would also appear to imply a positive bias in forecast errors for the model in the mid 2000s before the shift back down in mean growth in 2006Q1. We further investigate the possibility of overfitting, as well as robustness of our inferences about the Great Recession to different assumptions about structural change, including that a break in trend growth occurred in 2000Q2, in the next subsection. 


\subsection{How robust are inferences about the Great Recession?}

To the extent that there is uncertainty about the timing of an apparent structural break in trend growth or whether it is even best characterized by a single abrupt break (Stock and Watson, 2012; Eo and Kim, 2016; Antolin-Diaz, Drechsel and Petrella, 2017; Kim and Chon, 2020), it is important to investigate the robustness of our inferences regarding the nature of the Great Recession to different assumptions about structural change. To do so, we consider the following alternative cases for trend growth: no break; a break in 2000Q2; gradual change addressed by dynamically demeaning output growth rate using a backwardlooking rolling 40-quarter average growth rate, as in Kamber, Morley and Wong (2018); and gradual change addressed by using weighted-average inferences based on the relative profile likelihood value over all of the possible breakdates, as discussed in more detail below.

Table 7 reports the parameter estimates for our Markov-switching model under the first three assumptions for trend growth of no break, a break in 2000Q2, and gradual change addressed by dynamic demeaning. ${ }^{19}$ Notably, for all three of these alternative assumptions, the parameter estimates related to the effects of recessions are highly robust and similar to the estimates for the benchmark model in Table 3. Meanwhile, looking at the log likelihood values, the fit for dynamic demeaning and especially the no break case is worse than in the benchmark case or when allowing for a break in 2000Q2. ${ }^{20}$

For weighted-average inferences to capture possible gradual change, we calculate probabilistic weights over different possible breakdates in trend growth. In particular, using

\footnotetext{
${ }^{19}$ Following Kamber, Morley and Wong (2018), dynamic demeaning involves calculating deviations from a slowly-moving time-varying unconditional mean as follows: $\Delta \tilde{y}_{t} \equiv \Delta y_{t}-\frac{1}{40} \sum_{j=0}^{39} \Delta y_{t-j}$. We then estimate our Markov-switching model in (2) using the dynamically-demeaned data $\Delta \tilde{y}_{t}$ and setting $\delta=0$, with the residual volatility breakdate still fixed at $\tau_{v}=1984 \mathrm{Q} 2$ and $m=5$ for direct comparison to the benchmark case.

${ }^{20}$ Another way to look at model fit is to consider whether the filtered estimates of the residuals display serial correlation. Interestingly, over the subsample from 1984Q3 to 2018Q4, we find that the benchmark model with a break in 2006Q1 has the smallest Ljung-Box Q-statistics of 0.00 (1 lag) and 2.80 (4 lags). The model with a break in 2000Q2 has Q-statistics of 0.09 (1 lag) and 4.16 (4 lags), with the worse fit possibly reflecting a positive bias in forecast errors in the mid 2000s, as discussed in the previous subsection, although we note that, consistent with log likelihood, the model with a break in 2000Q2 has the smallest Q statistics (but very similar to those for the benchmark model) when considering the full sample. The model with dynamic demeaning performs similarly to the model with a break in 2000Q2 with Q-statistics of 0.30 (1 lag) and 3.60 (4 lags). Meanwhile, the model with no break has much larger Q-statistics of 2.14 (1 lag) and 12.20 (4 lags), the latter of which is significant at a $5 \%$ level. The significant deterioration of fit presumably reflects negative bias in forecast errors since at least 2006Q1 by failing to account a structural break in trend growth.
} 
Table 7: Parameter estimates under different assumptions about structural change

\begin{tabular}{|c|c|c|c|c|c|c|}
\hline \multirow[b]{2}{*}{ Parameter } & \multicolumn{2}{|c|}{ No break } & \multicolumn{2}{|c|}{ Break in 2000Q2 } & \multicolumn{2}{|c|}{ Dynamic Demeaning } \\
\hline & Estimate & S.E. & Estimate & S.E. & Estimate & S.E. \\
\hline$p_{01}$ & 0.02 & 0.01 & 0.02 & 0.01 & 0.03 & 0.02 \\
\hline$p_{02}$ & 0.02 & 0.01 & 0.02 & 0.01 & 0.02 & 0.01 \\
\hline$p_{11}$ & 0.65 & 0.21 & 0.67 & 0.15 & 0.74 & 0.10 \\
\hline$p_{22}$ & 0.73 & 0.12 & 0.72 & 0.13 & 0.73 & 0.12 \\
\hline$\mu_{0}$ & 0.77 & 0.04 & 0.94 & 0.05 & 0.09 & 0.04 \\
\hline$\mu_{1}$ & -1.48 & 0.29 & -1.55 & 0.21 & -1.19 & 0.15 \\
\hline$\mu_{2}$ & -2.03 & 0.28 & -2.10 & 0.29 & -2.11 & 0.270 \\
\hline$\lambda_{2}$ & 0.41 & 0.06 & 0.42 & 0.06 & 0.42 & 0.05 \\
\hline$\delta$ & & & -0.39 & 0.07 & & \\
\hline$\sigma_{v 0}$ & 0.93 & 0.07 & 0.90 & 0.07 & 0.87 & 0.06 \\
\hline$\sigma_{v 1}$ & 0.46 & 0.03 & 0.42 & 0.03 & 0.43 & 0.03 \\
\hline log-lik & -329.10 & & -315.05 & & -321.21 & \\
\hline
\end{tabular}

Note: The model specification is the same as the benchmark case in (2) with $\tau_{v}=1984 \mathrm{Q} 2$ and $m=5$, but with the following assumptions for trend growth: i) no break; ii) $\tau=2000 \mathrm{Q} 2$; and iii) structural change is gradual and can be captured by a backward-looking rolling 40-quarter average growth rate.

the profile likelihood value for each breakdate, the probabilistic weight for a breakdate $\tau$ is calculated as follows:

$$
\hat{w}(\tau) \equiv \frac{f\left(y \mid \hat{\theta}_{\tau} ; \tau\right)}{\sum_{t \in[0.1 T, 0.9 T]} f\left(y \mid \hat{\theta}_{t} ; t\right)},
$$

where $f\left(y \mid \hat{\theta}_{\tau} ; \tau\right)$ is the likelihood value for the trend growth breakdate $\tau$ given the model in (2) with maximum likelihood estimates $\hat{\theta}_{\tau}$ for the other parameters conditional on $\tau$, $\tau_{v}=1984 \mathrm{Q} 2$, and $m=5$. By construction, the sum of the weights over the possible breakdates will equal one, $\sum_{\tau} \hat{w}(\tau)=1$. Then, for example, the weighted-average smoothed probability of the regime $j$ at time $t$ given these weights is $\sum_{\tau} \hat{w}(\tau) \cdot \operatorname{Pr}\left[S_{t}=j \mid \Omega_{T}, \tau\right]$, where $\operatorname{Pr}\left[S_{t}=j \mid \Omega_{T}, \tau\right]$ is the smoothed probability of the regime $j$ at time $t$ given the breakdate of $\tau$. Weighted-average inferences inherently lose precision compared to knowing the exact breakdate, but they are potentially robust to multiple breaks in trend growth.

Figure 9 plots smoothed probabilities of the two contractionary regimes over time for the weighted-average approach, along with the different assumptions about structural change reported in Table 7 . The classification of certain recessions differs across the various cases 
Figure 9: Smoothed probabilities of contractionary regimes for different cases

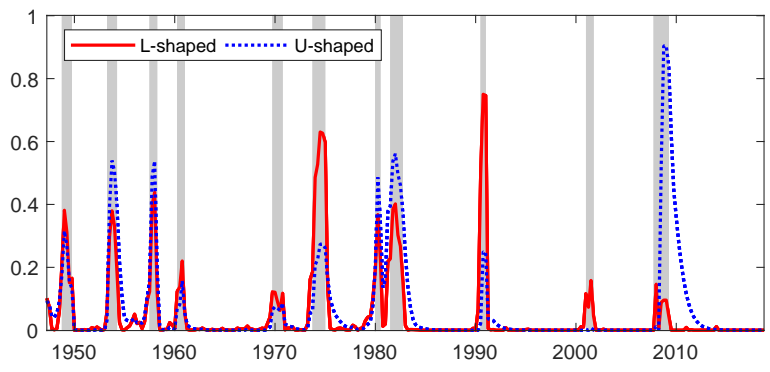

(a) Weighted average over possible breakdates

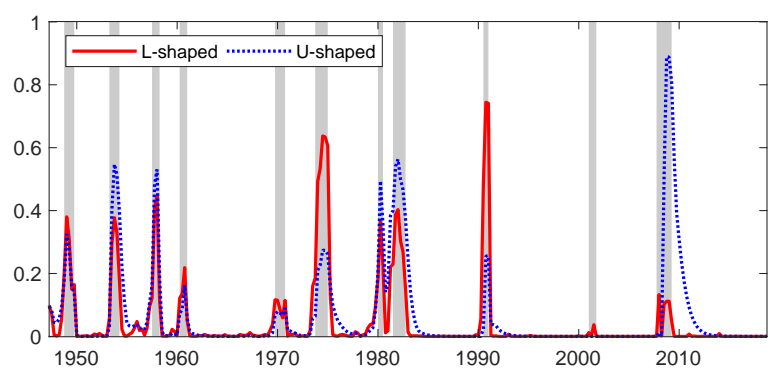

(c) Break in 2000Q2

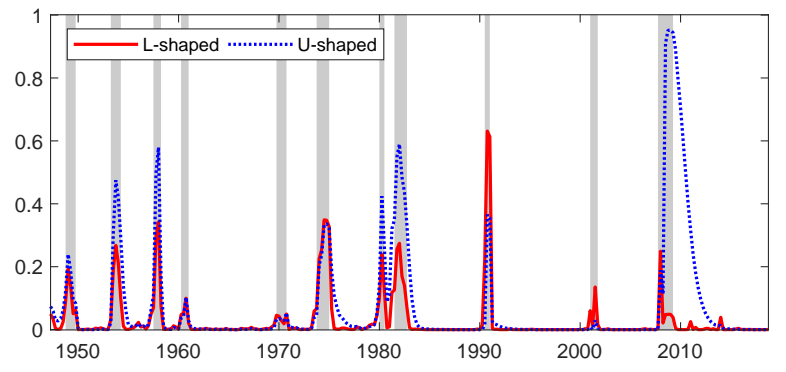

(b) No break

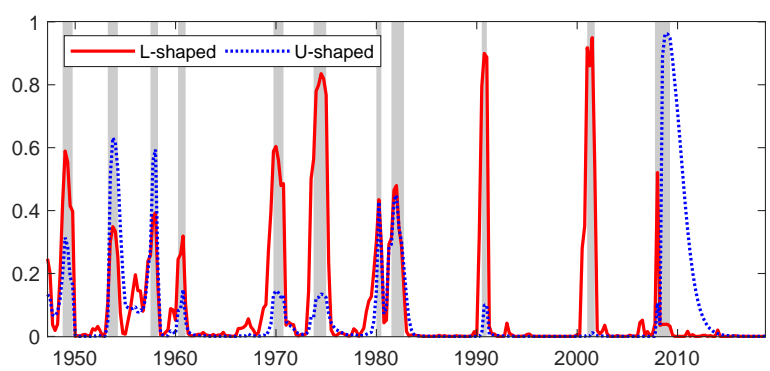

(d) Dynamic demeaning

Note: The shaded areas denote NBER recession dates.

and sometimes in comparison to the benchmark results in Figure 4. For example, it is clear that considering the trend growth break in 2000Q2 means that the 2001 recession would no longer be classified as a contractionary regime, supporting the idea that this timing for the structural break may be overfitting the temporary effects of the recession on growth rates. ${ }^{21}$ However, despite different inferences about some of the recessions, the Great Recession is always classified as being $\mathrm{U}$ shaped. Thus, we can be confident that our inferences about the nature of the Great Recession in particular are robust to different assumptions about structural change in trend growth.

As with our benchmark model, a direct implication of the smoothed probabilities in Figure 9 is that the Great Recession corresponded to a large persistent negative output gap. This is illustrated in Figure 10, which plots log real GDP and the estimated trend around the Great Recession for the different cases. In every case, consistent with a persistent negative

\footnotetext{
${ }^{21}$ The behavior of other variables such as the unemployment rate at the time provides a strong signal that there was actually a recession.
} 
Figure 10: Output and trend around the Great Recession for different cases

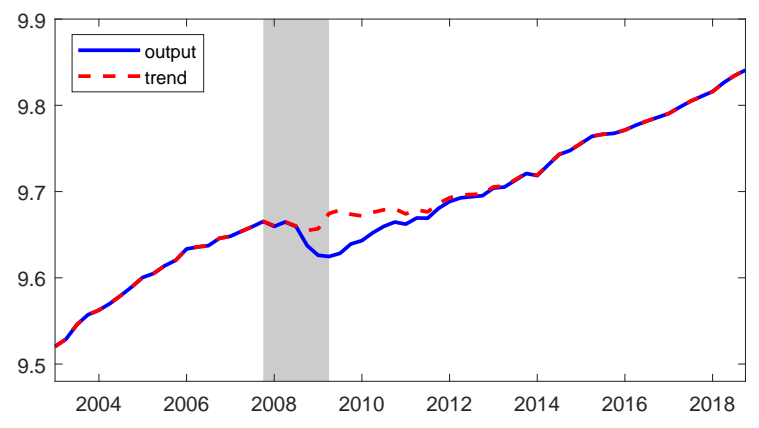

(a) Weighted average over possible breakdates

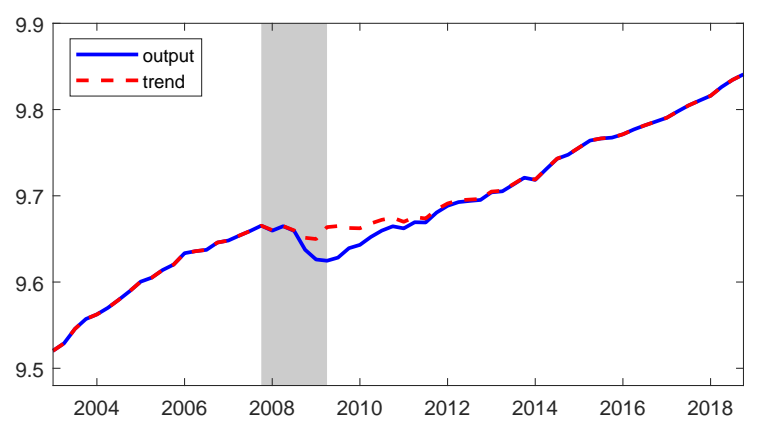

(c) Break in 2000Q2

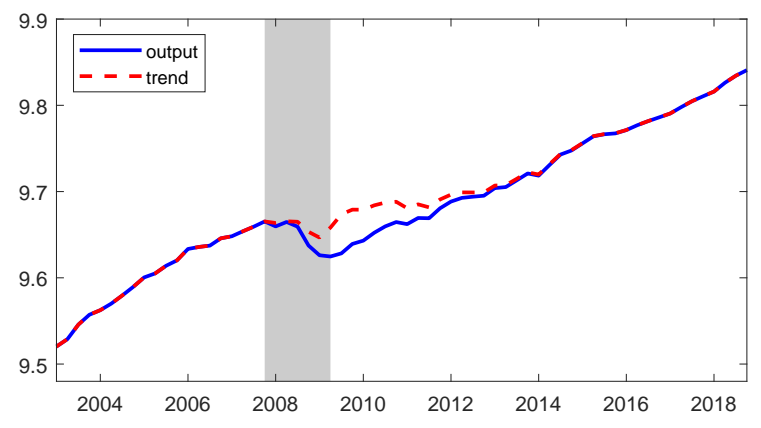

(b) No break

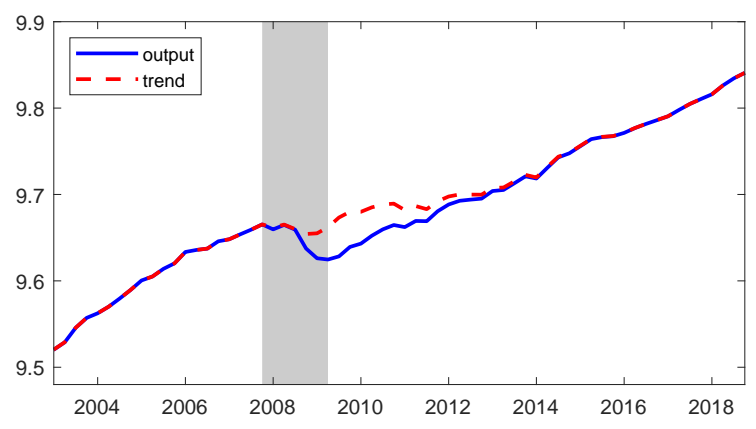

(d) Dynamic demeaning

Note: The shaded area denotes the Great Recession.

output gap, real GDP falls below trend in the Great Recession and remains well below trend for a number of years after the end of the recession. However, it is noticeable that the persistence of the implied output gap varies somewhat across the different alternatives and, in some cases, implies the economy was back at trend even though the unemployment rate was still quite elevated at the time. There is a literature documenting time variation in Okun's Law, especially after the Great Recession (Owyang and Sekhposyan, 2012; Grant, 2018). Yet, it is important to consider whether the estimated persistence of the output gap following the Great Recession is in some way constrained by the structure of our Markovswitching model.

To consider how the structure of our Markov-switching model interacts with inferences about the persistence of the output gap following the Great Recession, we extend the benchmark model in (2) to allow for a structural break in the length of the post-recession bounce- 
Figure 11: Smoothed probabilities of contractionary regimes for alternative parameters for the Great Recession

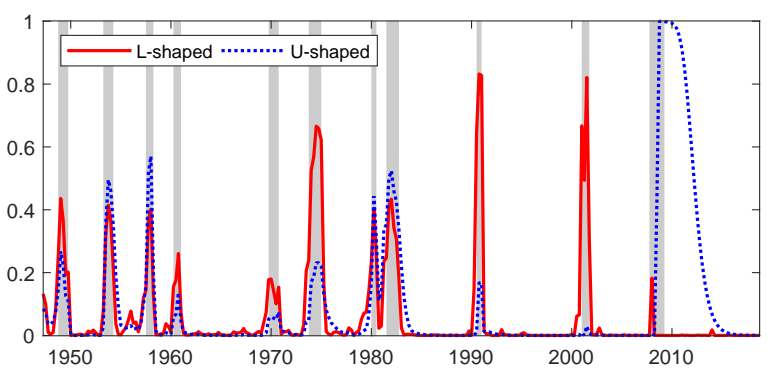

(a) $m^{\prime}=3$

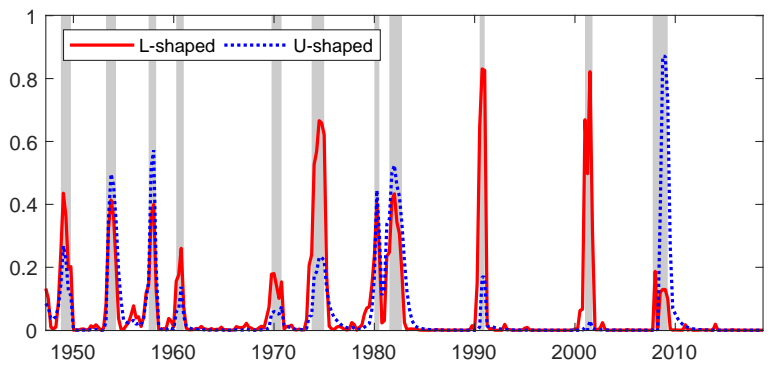

(c) $m^{\prime}=6$

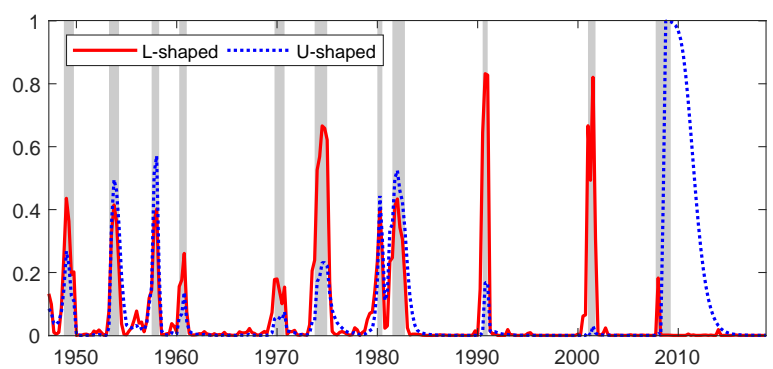

(b) $m^{\prime}=4$

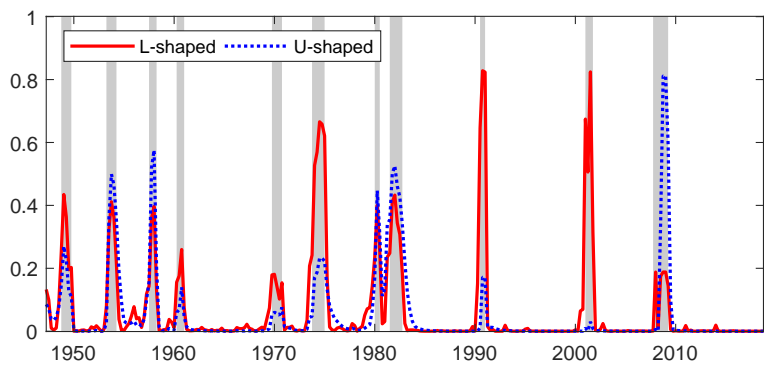

(d) $m^{\prime}=7$

Note: The shaded areas denote NBER recession dates.

back effect to $m^{\prime}=3,4,6,7$ with the Great Recession instead of $m=5$ for previous recessions. Figure 11 plots smoothed probabilities of the two contractionary regimes over time for the cases of $m^{\prime}=3,4,6,7$. It is clear that the length of time for which the probability of a U-shaped regime remains high after the Great Recession is quite sensitive to the value of $m^{\prime}$, with a smaller $m^{\prime}$ corresponding to a longer lasting U-shaped regime. The sensitivity in terms of length of the U-shaped regime directly translates into sensitivity in the persistence of the estimated output gap, as can be seen in Figure 12. For $m^{\prime}=3,4$, the estimated output gap is more persistent than in the benchmark case of $m^{\prime}=m=5$ and does not close until around 2015. For $m^{\prime}=6,7$, the estimated output gap is less persistent and closes soon after the end of the Great Recession. ${ }^{22}$

\footnotetext{
${ }^{22}$ To understand this result econometrically, note that, given a similar estimated negative effect of the Ushaped regime $\hat{\mu}_{2}$ across models with different $m^{\prime}$, a smaller $m^{\prime}$ directly implies a larger quarter-by-quarter bounceback effect $\hat{\lambda}_{2}^{\prime}$. Because the recovery from the Great Recession was only gradual, this implied strong bounceback is offset by the model attributing a high probability that the U-shaped regime persisted well beyond the end of the recession. By contrast, when $m^{\prime}=6,7$, the quarter-by-quarter bounceback effect $\hat{\lambda}_{2}^{\prime}$ is smaller and not be sufficient to offset $\hat{\mu}_{2}$ in order to capture positive but weak growth in real GDP
} 
Figure 12: Estimated output gap for alternative length of the post-recession bounceback effect for the Great Recession

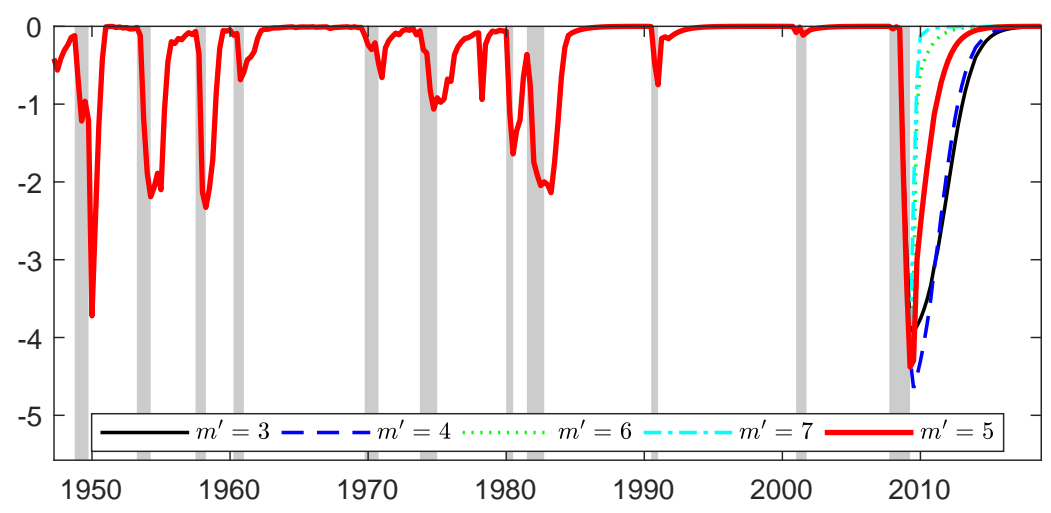

Note: The shaded areas denote NBER recession dates.

In terms of which $m^{\prime}$ to choose, we note that the likelihood values for the models with different $m^{\prime}$ are all very similar to that of the benchmark model, ranging only from -317.35 to -317.34. However, the relative robustness of the inference about the persistence of the output gap for $m^{\prime}=3,4$ compared to the higher values of $m^{\prime}$ suggests that the higher values mechanically impose constraints on the estimated persistence of the output gap that the lower values do not. ${ }^{23}$ Furthermore, the external consideration of the elevated unemployment rate in the United States above $6 \%$ until the middle of 2014 would also seem to support the models with $m^{\prime}=3,4$. However, the key point is that the inference about the Great Recession being U-shaped is completely robust to different possible values of $m^{\prime} .^{24}$

immediately following the recession, but before the full recovery. Thus, in these cases, the model attributes a very low probability that the U-shaped regime persisted beyond the end of the Great Recession.

${ }^{23}$ The likely offsetting benefit of the higher values of $m^{\prime}$ is that they can capture a smaller quarter-byquarter bounceback effect.

${ }^{24}$ Because the low probability of an L-shaped regime in the Great Recession could be due to the smaller estimated contractionary effect $\hat{\mu}_{1}$ compared to $\hat{\mu}_{2}$ that is evident in Figure 1 and Table 3, we also considered model with a structural break in $\mu_{1}$ to $\mu_{1}^{\prime}$ with the Great Recession. The estimated $\hat{\mu}_{1}^{\prime}=-1.92 \mathrm{does}$ result in an increase in the probability that the Great Recession was L shaped, but the probability of U-shaped regime is still higher, with the results very similar to those for $m^{\prime}=7$ in Figure 11. 


\section{Conclusion}

We have developed a new Markov-switching model of real GDP growth that accommodates two different types of recessions and allows for structural change in trend growth. Applying our model to U.S. data, we find that, perhaps surprisingly, the Great Recession was U shaped and did not appear to have any substantial hysteresis effects. Instead, the Great Recession generated a large persistent negative output gap, with the economy eventually recovering to a lower-growth trend path that, consistent with Fernald et al. (2017), appears to be due to a reduction in productivity growth that began no later than 2006. We highlight that our inferences about the timing of the output growth slowdown are sharpened by our consideration of a time series model that accounts for nonlinear dynamics of recessions. Meanwhile, our inferences about the nature of the Great Recession as generating a persistent negative output gap rather than large hysteresis effects is highly robust to different assumptions regarding the nature of structural change in trend growth.

Our analysis is univariate and we leave consideration of the implications of our findings for a multivariate setting to future research. However, we note that, similar to the conclusions in Huang and Luo (2018), our estimated output gap can clearly help explain weak inflation

in the years immediately after the Great Recession. Our results also suggest that the slow growth of the U.S. economy is likely to persist even when the recession related to the COVID19 crisis ends and interest rates eventually move back above the zero-lower-bound again. In terms of how the model will classify this latest recession, it is likely to depend on policy responses and require data from the recovery period to discriminate between L- and Ushaped possibilities. Thus, we also leave this to future research. 


\section{References}

Antolin-Diaz, Juan, Thomas Drechsel, and Ivan Petrella. 2017. "Tracking the Slowdown in Long-Run GDP Growth." Review of Economics and Statistics, 99(2): 343-356.

Auroba, S. Boragan, Luigi Bocola, and Frank Schorfheide. 2013. "Assessing DSGE Model Nonlinearities." Journal of Economic Dynamics and Control, 83: 127-142.

Bai, Jushan, and Pierre Perron. 1998. "Estimating and Testing Linear Models with Multiple Structural Changes." Econometrica, 66(1): 47-78.

Bai, Jushan, and Pierre Perron. 2003. "Computation and Analysis of Multiple Structural Change Models." Journal of Applied Econometrics, 18(1): 1-22.

Ball, Laurence. 2014. "Long-Term Damage from the Great Recession in OECD Countries." European Journal of Economics and Economic Policies: Intervention, 11(2): 149-160.

Baqaee, David Rezza, and Emmanuel Farhi. 2019. "The Macroeconomic Impact of Microeconomic Shocks: Beyond Hulten's Theorem." Econometrica, 87(4): 1155-1203.

Beveridge, Stephen, and Charles R Nelson. 1981. "A New Approach to Decomposition of Economic Time Series into Permanent and Transitory Components with Particular Attention to Measurement of the 'Business Cycle'." Journal of Monetary Economics, 7(2): 151-174.

Blanchard, Olivier, Eugenio Cerutti, and Lawrence Summers. 2015. "Inflation and Activity - Two Explorations and Their Monetary Policy Implications." IMF Working Paper $\mathrm{WP} / 15 / 230$.

Blanchard, Olivier J, and Lawrence H Summers. 1986. "Hysteresis and the European unemployment problem." NBER Macroeconomics Annual, 1: 15-78.

Carrasco, Marine, Liang Hu, and Werner Ploberger. 2014. "Optimal Test for Markov Switching Parameters." Econometrica, 82(2): 765-784.

Cerra, Valerie, and Sweta Chaman Saxena. 2008. "Growth Dynamics: The Myth of Economic Recovery." American Economic Review, 98(1): 439-457. 
Cerra, Valerie, and Sweta Chaman Saxena. 2017. "Booms, Crises, and Recoveries: A New Paradigm of the Business Cycle and its Policy Implications." IMF Working Paper $\mathrm{WP} / 17 / 250$.

DeLong, J. Bradford, and Lawrence H. Summers. 1988. "How Does Macroeconomic Policy Affect Output?" Brookings Papers on Economic Activity, 2: 433-480.

Dupraz, Stéphane, Emi Nakamura, and Jón Steinsson. 2019. "A Plucking Model of Business Cycles." NBER Working Paper No. 26351.

Eo, Yunjong, and Chang-Jin Kim. 2016. "Markov-Switching Models with Evolving RegimeSpecific Parameters: Are Postwar Booms or Recessions All Alike?" Review of Economics and Statistics, 98(5): 940-949.

Eo, Yunjong, and James Morley. 2015. "Likelihood-Ratio-Based Confidence Sets for the Timing of Structural Breaks." Quantitative Economics, 6(2): 463-497.

Fernald, John G, Robert E Hall, James H Stock, and Mark W Watson. 2017. "The Disappointing Recovery of Output after 2009." Brookings Papers on Economic Activity.

Friedman, Milton. 1964. "Monetary Studies of the National Bureau." In The National Bureau Enters Its 45th Year. Vol. 44, 7-25. NBER.

Friedman, Milton. 1993. "The "Plucking Model" of Business Fluctuations Revisited." Economic Inquiry, 31: 171-177.

Gordon, Robert J. 2003. "Exploding Productivity Growth: Context, Causes, and Implications." Brookings Papers on Economic Activity, 2003(2): 207-298.

Gordon, Robert J. 2015. "Secular Stagnation: A Supply-Side View." American Economic Review, 105(5): 54-59.

Gordon, Robert J. 2016. The Rise and Fall of American Growth: The U.S. Standard of Living since the Civil War. Princeton University Press, New Haven.

Grant, Angelia L. 2018. "The Great Recession and Okun's law." Economic Modelling, 69: 291-300. 
Grant, Angelia L, and Joshua CC Chan. 2017. "A Bayesian Model Comparison for TrendCycle Decompositions of Output." Journal of Money, Credit and Banking, 49(2-3): 525552.

Guerrieri, Luca, and Matteo Iacoviello. 2016. "Collateral Constraints and Macroeconomic Asymmetries." Journal of Monetary Economics, 90: 28-49.

Guerron-Quintana, Pablo A., and Ryo Jinnai. 2019. "Financial Frictions, Trends, and the Great Recession." Quantitative Economics, 10(2): 735-773.

Hamilton, James D. 1989. "A New Approach to the Economic Analysis of Nonstationary Time Series and the Business Cycle." Econometrica, 57(2): 357-84.

Hansen, Alvin H. 1939. "Economic Progress and Declining Population Growth." American Economic Review, 29(1): 1-15.

Huang, Yu-Fan, and Sui Luo. 2018. "Potential Output and Inflation Dynamics after the Great Recession." Empirical Economics, 55(2): 495-517.

Huang, Yu-Fan, Sui Luo, and Richard Startz. 2016. "Are Recoveries All the Same: GDP and TFP?" SSRN Working Paper No. 2988263.

Jordà, Òscar, Moritz Schularick, and Alan M Taylor. 2017. "Macrofinancial History and the New Business Cycle Facts." NBER Macroeconomics Annual, 31(1): 213-263.

Kamber, Güneş, James Morley, and Benjamin Wong. 2018. "Intuitive and Reliable Estimates of the Output Gap from a Beveridge-Nelson Filter." Review of Economics and Statistics, 100(3): 550-566.

Kim, Chang-Jin, and Charles R. Nelson. 1999a. "Friedman's Plucking Model of Business Fluctuations: Tests and Estimates of Permanent and Transitory Components." Journal of Money, Credit and Banking, 31(3): 317-34.

Kim, Chang-Jin, and Charles R. Nelson. 1999b. "Has the U.S. Economy Become More Stable? A Bayesian Approach Based on a Markov-Switching Model of the Business Cycle." Review of Economics and Statistics, 81(4): 608-616. 
Kim, Chang-Jin, and Christian J Murray. 2002. "Permanent and Transitory Components of Recessions." Empirical Economics, 27(2): 163-183.

Kim, Chang-Jin, and Jeremy Piger. 2002. "Common Stochastic Trends, Common Cycles, and Asymmetry in Economic Fluctuations." Journal of Monetary Economics, 49(6): 11891211.

Kim, Chang-Jin, James Morley, and Jeremy Piger. 2005. "Nonlinearity and the Permanent Effects of Recessions." Journal of Applied Econometrics, 20(2): 291-309.

Kim, Chang-Jin, Jeremy M Piger, and Richard Startz. 2007. "The Dynamic Relationship between Permanent and Transitory Components of US Business Cycles." Journal of Money, Credit and Banking, 39(1): 187-204.

Kim, Jaeho, and Sora Chon. 2020. "Why Are Bayesian Trend-Cycle Decompositions of US Real GDP So Different?" Empirical Economics, 58: 1339-1354.

Luo, Sui, and Richard Startz. 2014. "Is It One Break or Ongoing Permanent Shocks that Explains US Real GDP?" Journal of Monetary Economics, 66: 155-163.

McConnell, Margaret M., and Gabriel Perez-Quiros. 2000. "Output Fluctuations in the United States: What Has Changed since the Early 1980's?" American Economic Review, 90(5): 1464-1476.

Morley, James. 2009. "Macroeconomics, Nonlinear Time Series in." In Encyclopedia of Complexity and System Science., ed. R.A. Meyers, 5325-5348. Springer, Berlin.

Morley, James. 2019. "The Business Cycle: Periodic Pandemic or Rollercoaster Ride?" International Journal of Economic Policy Studies, 13(2): 425-431.

Morley, James, and Irina B. Panovska. 2019. "Is Business Cycle Asymmetry Intrinsic in Industrialized Economies?" Macroeconomic Dynamics, forthcoming: 1-34.

Morley, James, and Jeremy Piger. 2008. "Trend/Cycle Decomposition of Regime-Switching Processes." Journal of Econometrics, 146(2): 220-226. 
Morley, James, and Jeremy Piger. 2012. "The Asymmetric Business Cycle." Review of Economics and Statistics, 94(1): 208-221.

Morley, James C, Charles R Nelson, and Eric Zivot. 2003. "Why Are the Beveridge-Nelson and Unobserved-Components Decompositions of GDP So Different?" The Review of Economics and Statistics, 85(2): 235-243.

Owyang, Michael T, and Tatevik Sekhposyan. 2012. "Okun's Law over the Business Cycle: Was the Great Recession All That Different?" Federal Reserve Bank of St. Louis Review, 94 (September/October): 399-418.

Qu, Zhongjun, and Pierre Perron. 2007. "Estimating and Testing Structural Changes in Multivariate Regressions." Econometrica, 75(2): 459-502.

Reinhart, Carmen M, and Kenneth S Rogoff. 2009. "The Aftermath of Financial Crises." American Economic Review, 99(2): 466-472.

Stock, James H, and Mark W Watson. 2012. "Disentangling the Channels of the 2007-2009 Recession." Brookings Papers on Economic Activity.

Summers, Lawrence H. 2014. "US Economic Prospects: Secular Stagnation, Hysteresis, and the Zero Lower Bound." Business Economics, 49(2): 65-73.

Summers, Lawrence H. 2015. "Demand Side Secular Stagnation." American Economic Review, 105(5): 60-65. 